\title{
Legendagem e transferência intercultural: investigação e prática docente
}

María Dolores Lerma Sanchis

Recebido em: 14 de julho de 2017

Aceito em: 20 de julho de 2017
Professora do Departamento de Estudos Românicos da Universidade do Minho (UMinho), Portugal. Doutora e Mestre em Linguística pela Universidade do Minho. Áreas de investigação de interesse: tradução, tradução audiovisual, didática do Espanhol como Língua Estrangeira (ELE), linguística contrastiva, estudos culturais.

Contato: llerma@ilch.uminho.pt 
PALAVRAS-CHAVE:

legendasem; elementos

culturais; português-espanhol; didática.

KEYWORDS: translation; teaching; interference; naturalness; comparison Portuguese-Spanish.
Resumo: Neste artigo, apresentamos uma investigação sobre a tradução de referentes culturais para legendagem entre as línguas e culturas espanhola e portuguesa. $\bigcirc$ objetivo é identificar as técnicas de tradução preferidas e detectar tendências de tradução no corpus analisado. Paralelamente, refletimos sobre a aplicação didática de pesquisas deste género em unidades curriculares de ensino e aprendizagem da tradução para legendasem. Neste contexto, os estudantes devem atingir um bom domínio da competência cultural ou extralinguística.

Abstract: In this article we present a research on the translation of cultural references for subtitling between the Spanish and Portuguese languages and cultures. The goal is to identify preferred translation techniques and to detect translation norms in the corpus. Simultaneously, we reflect on the didactic application of this kind of researches in teaching and learning subtitling translation. In this context, students must achieve a good command of the cultural or extralinguistic competence. 


\section{INTRODUÇÃO}

Desde finais do século passado, a sociedade atravessa momentos de rápidas mudanças devidas à globalização e à implementação das tecnologias de informação e comunicação no quotidiano. Neste novo contexto, a Tradução Audiovisual (TAV), quer na ótica da investigação quer na perspetiva da didática, tem vindo a conquistar um espaço próprio que revela o papel central que desempenham no dia-a-dia as diferentes modalidades de $\mathrm{TAV}^{1}$. $\mathrm{O}$ aumento de publicaçóes e pesquisas sobre a matéria e o número representativo de centros de ensino superior que têm vindo a incorporar nos seus curricula unidades curriculares que formem profissionais na modalidade 2 é produto dessa circunstância.

Com o objetivo de aproximar a investigação às práticas pedagógicas, pretendemos refletir a respeito de problemáticas sobre as quais investigámos e que podem ser incorporadas na prática docente. Referimo-nos especificamente à tradução de elementos culturais entre as línguas e culturas portuguesa ${ }^{3}$ e espanhola na modalidade de legendagem.

Sobre o peso da combinação linguística em foco, lembramos os indicadores que situam o espanhol e o português dentro das cinco línguas

1 Principalmente dobragem, legendagem e o voice-over.

2 Numa busca pela base de dados da Universitat d'Alacant BITRA (Bibliografia de Interpretación y Traducción), selecionámos como palavra-chave o termo 'audiovisual' e restringimos a procura ao período de anos entre 2000 e 2017, obtivemos um total de 3.083 entradas (Consulta em 10 de junho 2017). Por outo lado, sobre os centros de ensino superior, num levantamento que efetuámos em 2015 através da consulta das páginas das universidades portuguesas, constatámos a existência de treze Unidades Curriculares relacionadas com a TAV, em sete estabelecimentos de ensino superior portugueses.

3 A investigação apresentada se foca no espaço linguístico e cultural do português europeu. 
mais usadas em internet e, principalmente, os dados sobre os fluxos comerciais entre Espanha e os países lusófonos que suportam o mercado para a tradução entre as duas línguas (Diaz Fouces, 2012). A proximidade geográfica, a facilidade de intercompreensão e o peso relativo das trocas comerciais entre países de expressão portuguesa e países de expressão espanhola justificam o interesse pelo conhecimento das duas língua e culturas. Nessa medida, Esperança (2016) indica como é valioso conhecer idiomas partilhados por comunidades amplas, sublinha a ideia de que nem todos os idiomas têm a mesma utilidade e sugere que conhecer a língua dos vizinhos é mais importante do que conhecer uma língua distante.

\section{TransferênCIA INTERCULTURAL E LEGendagem \\ 2.1. DESCRIÇÃO DA PESOUISA}

Objetivo principal é identificar as técnicas de tradução empregues na transferência dos elementos culturais (EC) presentes num corpus constituído por sete filmes do realizador Pedro Almodóvar ${ }^{4}$, cujos resultados permitirão conhecer o comportamento dos tradutores perante uma dificuldade concreta num corpus específico.

Para a seleção do corpus, seguimos o critério de homogeneidade quanto à procedência das produçóes, quanto à língua de origem e de chegada,

4 O corpus é composto pelas seguintes sete longas-metragens e as respetivas legendagens para português europeu: Todo sobre mi madre / Tudo sobre a mina mãe (1999), Hable con ella / Fala com ela (2002), La mala educación / Má educação (2004), Volver / Volver - Voltar (2006), Los abrazos rotos / Abraços desfeitos (2009), La piel que habito / A pele onde eu vivo (2011) e Los amantes pasajeros / Os amantes passageiros (2013). 
quanto ao género e quanto à delimitação espaço-temporal (Barambones, 2009), e tivemos em consideração os seguintes critérios:

i. A perspetiva empírica e descritiva adotada determina usar um corpus representativo, no sentido de facultar resultados significativos; e autêntico, na medida em que operamos com legendas profissionais de DVD.

ii. Almodóvar é o realizador espanhol com maior reconhecimento internacional. Em consequência, o estatuto de canonização atingido pela obra e pelo cineasta pressupóe uma legendagem executada com profissionalismo.

iii. A cinematografia de Almodóvar reflete aspetos significativos do quotidiano da cultura espanhola.

iv. Os filmes apresentam homogeneidade de género, situando-se entre o melodrama e a comédia.

v. As obras estrearam em salas de cinema portuguesas.

A Teoria dos Polissistemas e os Estudos Descritivos de Tradução (EDT) conformam o quadro teórico para estudar a tradução de EC, já que oferecem uma estrutura vasta, flexível e adaptável a contextos de investigação diversos, entre os quais à Tradução Audiovisual (Karamitroglou, 2000; Delabastita, 1989; Díaz-Cintas, 2001; Chaume, García de Toro, 2010). Aplicamos a teoria das normas (Toury, 1995), em particular focamonos nas normas linguístico-textuais que regem a seleção do material do repertório próprio que irá formular o texto traduzido e ocupará o lugar 
do material linguístico e textual do texto original, ou seja, as normas que afetam ao nível microtextual.

Sólo a partir de ejemplos reales, que existen y se han visto integrados en la sociedad de acogida, podemos extraer conclusiones que nos hagan avanzar en el conocimiento de la traducción. Y las normas son, precisamente, los útiles que nos ayudarán en esa tarea (Díaz-Cintas, 2005, 14).

Para efeitos desta pesquisa, entendemos por elementos culturais os elementos linguisticamente náo transparentes referidos a diferentes âmbitos e cuja interpretação não se deduz diretamente do seu significado de dicionário, mas sim do seu significado enciclopédico, ou seja, do conjunto de conhecimentos compartilhados pelos membros de uma comunidade particular, que não coincide necessariamente com o conjunto de pessoas que falam uma determinada língua. Incluímos elementos extralinguísticos vinculados à geografia, hábitos, história, modos de vida, etc., com um valor específico numa cultura concreta que, quando são transpostos para uma outra, podem originar problemas de traduçáo, seja porque náo existem, seja porque lhes são associadas conotaçôes diferentes nas duas culturas, daí a dificuldade em identificá-los e traduzi-los. Na medida em que o conhecimento enciclopédico é variável e pode alterar-se, as relaçōes interculturais também são vistas numa ótica dinâmica. Nessa linha de pensamento, os EC têm carácter relacional e existem ou não em relação às culturas concretas. 
A partir dos contributos sobre as técnicas para a tradução de EC propostas por diversos autores ${ }^{5}$, mas sobretudo a partir da observação e análise pormenorizada do corpus estudado, distinguimos seis categorias que correspondem às soluçóes encontradas no $\operatorname{corpus}^{6}$. As técnicas identificadas são: a repetição, a traduçáo literal, a tradução oficial, a explicitação, a adaptaçáo cultural e a omissáo, todas organizadas num contimuum que vai de acordo com a maior aproximação à cultura de origem ou à de chegada, evidenciando mais ou menos visibilidade do tradutor na manipulação do texto original durante o processo tradutório.

1 - Chamamos repetiçáo à técnica que consiste em conservar ou repetir, sem qualquer modificação, o termo do texto original (TO) no texto traduzido (TT). Esta técnica é tradicionalmente muito usada na legendagem portuguesa, pelo que o público está habituado e não costuma manifestar estranheza ante a presença de EC que lhe são alheios e desconhecidos, como acontece nos exemplos descritos a seguir, mesmo comportando perda de informação.

No primeiro exemplo, o referente da Casa de Campo funciona como mais uma marca que proporciona pistas para caracterizar a personagem. Se o espectador desconhece que este espaço foi um foco de prostituição em Madrid, perde parte da informação que o realizador usa na caracterização

5 Especialmente dos autores que abordam a problemática das técnicas de tradução de EC em textos audiovisuais como, Nedergaard-Larsen (1993), Tomaszkiewicz (2001), Díaz-Cintas \& Remael (2007), Gottlieb (2009), Leppihalme (2011), Pedersen (2011) e Chaume (2012).

6 Coincidimos com Martí Ferriol (2006) ao assinalar que uma classificação das técnicas de tradução entendida como aproximação a um problema particular, numa situação concreta, pode requerer uma categorização especificamente organizada para o estudo de um caso concreto. 
da personagem, dado que a técnica escolhida não amplia ou especifica a informação.

\begin{tabular}{|ll|}
\hline \multicolumn{2}{|c|}{ FILME: Volver - Voltar // Volver } \\
\hline TT & TO \\
- Vai para onde? & $-¿$ Adónde vas? \\
- Para a Casa de Campo, mas se & - A la Casa de Campo, pero con que \\
me deixar no centro já é fixe. & me dejes en el centro me viene bárbaro. \\
\hline
\end{tabular}

No segundo caso, o EC surge num diálogo mantido à saída do hospital entre uma mulher e o homem que acaba de receber o transplante do coração de Esteban, os escaldadillos ${ }^{7}$ irão compor a refeição para festejar a alegria da família. Escolhemos esta interação para mostrar como neste caso a função do EC permanece graças ao contexto e à expressividade das falas. Trata-se de um referente 'difícil' inclusive para o espectador original do filme, mas como o público de produtos legendados lê, ouve e vê em simultâneo, a possibilidade de intuir o significado pelo contexto, mesmo desconhecendo o EC, é maior.

\begin{tabular}{|ll|}
\hline \multicolumn{2}{|c|}{ FILME: Tudo sobre a minha mãe // Todo sobre mi madre } \\
\hline TT & TO \\
Os escaldadillos que te faço & ¿Qué escaldadillos te voy a hacer \\
mal cheguemos! & cuando lleguemos! \\
\hline
\end{tabular}

7 Expressão galega usada para referir um guiso galego com batatas e couve-galega ou berzas (Poyato, 2007). 
2 - A traduçáo literal consiste na transposição palavra por palavra de um termo ou sintagma. No momento de interpretar o fragmento traduzido, o sucesso da técnica depende da transparência da solução encontrada, do contexto e do apoio da imagem que acompanha a legenda. Ou seja, dos mesmos elementos que condicionam o tradutor na escolha da técnica. A preferência pela tradução literal manifesta uma vontade de alterar o mínimo possível do TO, uma vez que preserva as opções do realizador.

Nos exemplos escolhidos, a traduçáo literal é propiciada pela proximidade das línguas e a transparência dos termos. No primeiro caso, se trata do nome de um programa de televisão, uma espécie de reality show; no segundo, o tradutor opta pela tradução literal, apesar de existir em Portugal uma instituição equivalente que desenvolve atividades similares, a Organizaçáo Portuguesa de Transplantação (OPT).

\begin{tabular}{|c|c|}
\hline \multicolumn{2}{|c|}{ FILME: Volver - Voltar // Volver } \\
\hline TT & TO \\
\hline Sabes que ela é colaboradora & Ya sabes que ella es colaboradora \\
\hline do “Onde Quer Que Esteja!” & de Donde quiera que estés. \\
\hline \multicolumn{2}{|c|}{ FILME: Tudo sobre a minha mãe // Todo sobre mi madre } \\
\hline TT & TO \\
\hline Organizaçáo Nacional & Hola, Organización Nacional de \\
\hline de Transplantes, faça favor? & Trasplantes, dígame. \\
\hline
\end{tabular}

3 - Na tradução oficial, o tradutor opta por utilizar um equivalente préfixado já existente e aceite na cultura recetora. Esta técnica é usada em uma variedade de âmbitos culturais: topónimos, acontecimentos históricos, títulos de filmes, livros, etc. 


\begin{tabular}{|lc|}
\hline \multicolumn{2}{|c|}{ FILME: Fala com ela // Hable con ella } \\
\hline TT & TO \\
Passa-se na $\mathbf{1}^{\text {a }}$ Grande Guerra. & Es de la Primera Guerra Mundial. \\
\hline
\end{tabular}

\begin{tabular}{|l|l|}
\hline \multicolumn{2}{|c|}{ FILME: Abraços desfeitos //Los abrazos rotos } \\
\hline TT & TO \\
Procura Fim-de-semana no Ascensor, & Busca Ascensor para el cadalso \\
do Louis Malle. & de Louis Malle. \\
\hline Título original: Ascenseurpour l'échafaud (Malle, 1958) \\
\hline
\end{tabular}

\begin{tabular}{|ll|}
\hline \multicolumn{2}{|c|}{ FILME: Fala com ela // Hable con ella } \\
\hline TT & TO \\
O meu preferido é o de Havana. & Mi guía favorita es la de La Habana. \\
\hline
\end{tabular}

4 - A explicitaçáo ocorre quando a tradução apresenta um termo mais compreensível, através da especificação, da generalização ou da adição de informação. A técnica visa ultrapassar os obstáculos que possam surgir na compreensão de EC menos reconhecíveis. $\mathrm{O}$ recetor não perde informação, embora possa perder pormenores. As ocorrências apresentadas mostram situaçóes do uso da técnica em diferentes campos culturais: na alimentação, em marcas comerciais e nomes de personagens.

Destacamos o primeiro exemplo, que retrata uma transferência com explicitação de uma alcunha assumida pela personagem como nome próprio. Em todo o corpus, é a única ocasião em que é usado este género de explicitação ou glosa, marcada e destacada graficamente na legenda com o uso do parêntese. Este comportamento não é estranho na legendagem portuguesa, costumando ser utilizada em contextos que implicam duplos 
sentidos ou em jogos de palavras com termos homófonos ou homógrafos, e normalmente decorre da necessidade de tornar acessível ao público-alvo um significado ou uma ilação que, sendo bastante transparente no texto original, não o é na tradução.

\begin{tabular}{|ll|}
\hline \multicolumn{2}{|c|}{ FILME: Tudo sobre a minha mäe // Todo sobre mi madre } \\
\hline TT & TO \\
$\begin{array}{l}\text { Comecei a fumar por culpa } \\
\text { da Bette Davis, para a imitar. }\end{array}$ & $\begin{array}{l}\text { Empecé a fumar por culpa } \\
\text { De Bette Davis. Por imitarla. }\end{array}$ \\
E aos dezoito já fumava & A los dieciocho años, ya fumaba \\
como um camionista. & como un carretero. \\
Por isso me chamo Huma & Por eso, me puse Huma. \\
(Fuma). & \\
É um nome bonito... & Es un nombre bonito. \\
O fumo é a única coisa & Humo es lo único \\
que tenho de meu. & que ha habido en mi vida. \\
\hline
\end{tabular}

\begin{tabular}{|ll|}
\hline \multicolumn{2}{|c|}{ FILME: Volver - Voltar // Volver } \\
\hline TT & TO \\
Uns bolinhos de manteiga & Unos mantecados que se deshacen en el \\
que se desfazem na boca! & paladar. \\
\hline
\end{tabular}

\begin{tabular}{|ll|}
\hline \multicolumn{2}{|c|}{ FILME: Os amantes passageiros // Los amantes pasajeros } \\
\hline TT & TO \\
Espera, deixa ver a pulseira Cartier. & Espera, a ver ese Cartier. \\
\hline
\end{tabular}


5 - A adaptaçáo cultural acontece quando o EC original é substituído por outro pertencente à cultura recetora, porquanto o original dificilmente será compreendido na cultura de chegada. A mensagem adapta-se, assim, às necessidades da cultura-alvo.

\begin{tabular}{|lc|}
\hline \multicolumn{2}{|c|}{ FILME: Fala com ela // Hable con ella } \\
\hline TT & TO \\
Não te preocupes, & No te preocupes tanto tú, \\
a haver alguma coisa, & si pasara cualquier cosa, \\
& hoy en día \\
no TGV & con el $\boldsymbol{A V E}$ \\
póes-te cá em duas horas. & en dos horas estás aqui. \\
\hline
\end{tabular}

\begin{tabular}{|ll|}
\hline \multicolumn{2}{|c|}{ FILME: Tudo sobre a minha mãe // Todo sobre mi madre } \\
\hline TT & TO \\
A minha amiga e o marido & Mi amiga y su marido \\
das mamas montaram um quiosque, & con tetas, se montaron un chiringuito \\
ali mesmo, na Barceloneta. & aqui en la Barceloneta. \\
\hline
\end{tabular}

6 - A omissáo diz respeito à supressão de um EC. Em legendagem, uma referência cultural pode apresentar-se omitida por vários motivos: porque é obscura, porque é redundante, por necessidade de condensar o texto ou porque o tradutor desconhece a tradução correta (Chaume, 2012). Igualmente, a falta de um referente equivalente na cultura de chegada pode constituir um fator que imponha esta opção.

Na primeira ocorrência o referente cultural SAMUR, Servicio de Asistencia Municipal de Urgencia y Rescate de Madrid, é uma instituição semelhante ao INEM (Instituto Nacional de Emergência Médica) em Portugal. É 
possível que a omissão, embora pouco usada na legendagem portuguesa, seja uma opção que tente evitar a estranheza que produziria encontrar num texto estrangeiro uma instituição portuguesa como o INEM.

\begin{tabular}{|lc|}
\hline \multicolumn{2}{|c|}{ FILME: Abraços desfeitos // Abrazos rotos } \\
\hline TT & TO \\
- Diego, como te sentes? & \\
- Traz gelo, por favor. & $-{ }^{\text {TTrae hielo! }}$ \\
& Por favor, llamar al SAMUR. \\
\hline
\end{tabular}

\begin{tabular}{|ll|}
\hline \multicolumn{2}{|c|}{ FILME: Tudo sobre a minha mãe // Todo sobre mi madre } \\
\hline TT & TO \\
- Então vem tu lá para casa. & - Pues, vente a casa. \\
- Eu quero ficar sozinha. & - Quiero estar sola, Mamen. \\
\hline
\end{tabular}

\section{Alguins casos particulares}

Embora não seja o procedimento habitual, o mesmo referente mencionado diversas vezes no texto pode receber distinto tratamento tradutório em função da sua relevância na trama, da funcionalidade atribuída, de se é transmitido por diferentes canais de significação (som e imagem) em simultâneo, da extensão do termo, do grau de transculturalidade, etc.

Em Los amantes pasajeros circunscrevemos oito ocorrências de um mesmo referente que, na versão portuguesa, é transposto mediante três técnicas diferentes: a omissão (duas vezes), a tradução literal (três), e a explicitação com generalização (em três ocasiôes). Se trata da referência a uma bebida a agua de Valencia, originária e popular na cidade de Valência. Nesta ocasião, a opção do tradutor é orientada em cada momento de acordo com 
a funcionalidade, os constrangimentos de espaço e tempo, a imagem que facilita a contextualização. O termo surge com tradução literal no início e é omisso apenas quando é referido em momentos consecutivos. Finalmente, o mesmo EC é explicitado com o hiperónimo cocktail em circunstâncias em que pesam mais as limitaçóes espaço-temporais. $O$ resultado final responde a uma ótica funcional em que o público-alvo não é privado de informação, num contexto em que este já se tinha apercebido, graças às imagens, de que a bebida é um cocktail elaborado com sumo de laranja, cava e outras bebidas alcoólicas.

\begin{tabular}{|c|c|}
\hline \multicolumn{2}{|c|}{ Traduçáo literal } \\
\hline TT & TO \\
\hline $\begin{array}{l}00: 42: 32,287 \text {--> 00:42:35,245 } \\
\text { - Estamos a fazer Água de Valência. } \\
\text { - Excelente ideia! }\end{array}$ & Estamos haciendo agua de Valencia. \\
\hline $\begin{array}{l}\text { 00:45:50,287 --> 00:45:52,482 } \\
\text { Esta Água de Valência está bem boa. }\end{array}$ & Oye, está muy buena esta agua de Valencia. \\
\hline $\begin{array}{l}\text { 00:46:11,127 --> 00:46:14,597 } \\
\text { O Sr. Comandante desculpe, } \\
\text { mas acho piada ver dois machôes } \\
\text { 00:46:15,007 --> 00:46:17,646 } \\
\text { a falar de descontrair } \\
\text { e de Água de Valência }\end{array}$ & $\begin{array}{l}\text { Disculpe usted, señor comandante, } \\
\text { que me hace gracia ver } \\
\text { a dos hombretones como ustedes } \\
\text { hablando de desparramar, } \\
\text { de agua de Valencia, }\end{array}$ \\
\hline
\end{tabular}




\section{Omissáo}

¡Uy, agua de Valencia, qué buena idea!

00:50:01,607 --> 00:50:03,359

Um copinho, Sr. Mas?

¿Un vasito de agua de Valencia, Sr. Mas?

\section{Explicitaçáo}

00:42:54,207 --> 00:42:57,802

Mas eu não, deixei o álcool.

¡Yo no! Yo he dejado el alcohol.

O cocktail é para os passageiros.

El agua de Valencia_la estamos

haciendo para los pasajeros.

00:50:26,167 --> 00:50:29,000

- Menos mal...

- Adorava esse cocktail

- Me encantaba el agua de Valencia

nos anos 80 . en los 80 .

01:06:47,527 --> 01:06:50,280

- Estou maldisposta.

- Tengo arcadas.

- Não admira, com o que bebeste.

- ¡Normal! Te has puesto ciega

01:06:50,367 --> 01:06:53,245

a agua de Valencia.

- O que tem o cocktail a ver?

A mesma indefinição acompanha a tradução do termo mantecado, um doce típico espanhol, especialmente do Natal, que não faz parte da doçaria tradicional portuguesa. No filme Volver (2006), das três ocorrências em que é referido, em duas é usada a explicitação e na terceira, a repetição. Uma vez que a imagem não mostra o referente, a técnica da repetição pode provocar estranhamento nos espectadores. 


\begin{tabular}{|lc|}
\hline & Explicitaçáo \\
\hline $\begin{array}{l}\text { TT } \\
\text { 00:31:18,528 --> 00:31:21,167 } \\
\text { Uns bolinhos de manteiga } \\
\text { que se desfazem na boca! }\end{array}$ & TO \\
\hline & $\begin{array}{l}\text { Unos mantecados } \\
\text { que se deshacen en el paladar. }\end{array}$ \\
$\begin{array}{l}\text { 00:46:03,288 --> 00:46:06,758 } \\
\text { E a ti pago-te 4 caixas de doces, } \\
\text { em vez de 3. }\end{array}$ & $\begin{array}{l}\text { Y a ti, en vez de tres cajas de mantecados, } \\
\text { te voy a pagar cuatro. }\end{array}$ \\
\hline $\begin{array}{l}\text { 00:31:23,448 --> 00:31:25,723 } \\
\text { parece impossível } \\
\text { que tenhas trazido mantecados! }\end{array}$ & Repetiçáo \\
\hline
\end{tabular}

\section{SíNTESE DE DADOS}

No corpus foram identificadas um total de 483 ocorrências de EC pertencentes aos dezoito campos seguintes: nomes próprios, espaços públicos ou edifícios sociais, produçôes ou formas artísticas, alimentação, âmbito taurino, presença de outras línguas, músicas, instituiçōes, educação, festividades, história, meios de comunicação social, habitação, rituais sociais, moda, elementos da natureza, marcas comerciais e âmbito político. A posteriori, constatamos que os campos incluídos na nossa categorizaçáo coincidem com os descritores apresentados no capítulo do PCIC sobre referentes culturais.

Os resultados da análise revelam a existência de uma tendência bastante uniforme em todo o corpus, que se manifesta na preferência pela repetiçáo 
$(59,2 \%)$ como técnica mais usada, seguida pela traduçáo oficial $(21,8 \%)$. As restantes técnicas ocupam lugares mais discretos: a explicitaçáo, em terceiro lugar (9,8\%); a traduçáo literal, em quarto (4,1\%); a omissáo, em quinto (3,6\%); e, por último, a adaptaçáo cultural (1,42\%). Estes dados permitem retirar as seguintes conclusóes em relação com o uso das técnicas de tradução aplicadas aos EC do corpus:

A repetiçáo, a técnica mais usada, garante a conservação do referente cultural e revela uma vontade de exotização, de aproximar o recetor à cultura de origem do texto e, em última instância, de fidelidade ao original. Todavia, se o recetor não reconhece o EC, a função que desempenha no texto original perde-se no texto de chegada. Por um lado, pode ser vista como uma solução fácil e de pouco risco; por outro, o seu uso tem de ser ponderado para não provocar excessivo desconforto nos recetores ao sentirem que perdem informaçáo importante para a narrativa. Neste ponto náo podemos esquecer a centralidade da imagem que acompanham as legendas, bem como a presença simultânea da língua original. Ambos elementos de significação contribuem para explicitar e recuperar o papel exercido pelo EC. Não obstante, a proximidade linguística e cultural e as novas tecnologias fazem com que o público esteja cada vez mais familiarizado com outras culturas.

A traduçáo oficial é a segunda técnica mais utilizada. Inevitavelmente a proximidade cultural justifica o facto de que uma boa parte dos EC sejam comuns, tendo a sua própria designação em cada língua. Encontramos abundantes exemplos na transposição de topónimos, dado que em 
português, como acontece noutras línguas, quando existe uma tradução oficial de um topónimo, opta-se pelo nome sancionado. A mesma técnica é usada também para transpor as referências às formas artísticas provenientes de culturas estrangeiras, concretamente, quando são referidos títulos de filmes, peças de teatro, músicas etc., exceto no caso de se referirem a títulos fictícios, em que se opta sempre pela tradução literal.

Surpreende positivamente o baixo número de ocorrências de traduçóes literais. A soluçăo é pouco usada, mas está distribuída pelos diferentes campos culturais. A técnica é empregue nas referências relativas a produções artísticas sem existência fora do filme, como no exemplo a referência ao filme Chicas y maletas > Miúdas e malas (Los abrazos rotos), onde é feita uma velada alusão a um filme anterior do realizador, Mujeres al borde de un ataque de nervios (1988), mas a intertextualidade náo nos parece transparente nem para o público original nem para o português. Surge também no inesperado caso em que o título de um filme estrangeiro ${ }^{8}$ é transposto literalmente de espanhol para português, Cómo casarse con un millonario > Como Casar com um Milionário, em vez da tradução oficial, Como se conquista um milionário (Todo sobre mi madre). A traduçáo literal é um recurso considerado fácil, que origina decalques, e não é estranho em traduçôes na combinaçáo linguística de espanhol e português em qualquer uma das direçóes. Poderemos, pois, interpretar esta baixa densidade de ocorrências como sinal de cuidado por parte dos tradutores.

8 Trata-se do filme norte-americano How to Marry a Millionaire realizado por Jean Negulesco (1953). 
Mediante a explicitaçáo, o tradutor procura um termo mais próximo e transparente para a cultura de chegada. Em todo o corpus existem exemplos de variados campos: desde a alimentação, Benjamines de champán > Garrafinhas de champanhe (Los amantes pasajeros); o âmbito taurino, albero > arena (Hable con ella); elementos da natureza, viento solano > vento de leste (Volver); no campo da habitação, pazo > casarão (La piel que habito) etc. A explicitação aproxima o texto do recetor. Dentro do continuum em que situamos as técnicas identificadas no corpus, implica uma soluçáo de tradução inclinada para a cultura de chegada, que aproxima o texto do recetor e permite a preservação do referente por meio de um termo mais compreensível. Esta prática costuma ser útil e segura quando não existe uma tradução oficial e quando não é boa opção o recurso a soluções extremas desnecessárias, seja mediante repetição ou a omissão.

Não nos admira o recurso mínimo à adaptação cultural, que provoca a naturalização do EC, já que a experiência e a observação atenta às legendagens portuguesas de produtos de ficção habituaram-nos a essa regularidade nos procedimentos dos tradutores. Ao contrário da dobragem, a legendagem é uma modalidade menos propensa ao uso da adaptação cultural, a qual levada ao extremo implica uma tendência domesticadora da versão traduzida que linguística e culturalmente minimiza os elementos caracterizadores da obra original e do estilo do autor. No corpus localizámos ocorrências como por exemplo chiringuito > quiosque (Todo sobre mi madre); chalé > casita de campo (Volver); ou ainda guardia civil > brigada de trânsito (Má educação). 
Na legendagem para português, a omissáo é uma opção pouco usada, apenas diz respeito a 3,5\% dos exemplos. Visto que o público português está habituado a ouvir línguas estrangeiras e sente facilidade em comunicar facilmente em inglês e em espanhol, o tradutor pondera o uso para evitar a crítica fácil do espectador que está à espera de ler os diálogos completos das personagens. De facto, na tradução entre línguas próximas é habitual uma tendência para soluçôes mais imediatas e literais. $\mathrm{O}$ corpus contém omissōes variadas, designadamente, em traduçôes de termos que ocupam muito espaço ou que já surgiram noutro momento e têm o apoio da imagem.

\section{Aplicaçäo didÁtica}

Do ponto de vista da didática da tradução a competência intercultural, também chamada de extralinguística ou cultural, assume um lugar relevante dentro das competências do tradutor profissional (Kelly, 2002; Cerezo, 2012; Gutiérrez, 2016; PACTE, 2003, entre outros). Tanto é assim que, a partir da revisão das propostas de diversos autores sobre as competências em TAV, Cerezo (2012) elabora uma listagem de trinta competências genéricas e vinte e sete específicas, consideradas significativas para o exercício da traduçáo audiovisual profissional. Os resultados obtidos mostram que, entre as competências genéricas, a relativa ao conhecimento da cultura e hábitos de outros países ocupa o quinto lugar, na opiniáo dos professores de TAV; o décimo primeiro, para os tradutores e o nono lugar para os empregadores. No que se refere às competências específicas, a 
competência cultural é indicada em sexto lugar pelos docentes, em quarto pelos tradutores e em décimo primeiro pelos empregadores.

Especificamente para a didática da legendagem, Skuggevik (2009) distingue cinco níveis de competências. O conhecimento dos aspetos culturais e sociais e a perceção do seu valor surge em terceiro lugar. Numa perspetiva holística, o quinto nível pertence a uma macrocompetência que agrupa as anteriores e estabelece os procedimentos adequados para formular as legendas em cada situação.

Os dados anteriores evidenciam a importância do conhecimento das realidades culturais e do domínio dos processos de transferência dessas mesmas referências culturais.

Por outra parte, no âmbito do ensino e aprendizagem de línguas estrangeiras, próximo ao da tradução, existem dois importantes documentos: o Quadro europeu comum de referência para as linguas (QECRL), para o espaço europeu, e o Plan Curricular del Instituto Cervantes (PCIC), especificamente para a língua espanhola. Em concreto, no QECRL são abordadas questóes relacionadas com o ensino e aprendizagem das competências gerais, que dentro do conhecimento declarativo incluem os saberes culturais, socioculturais e interculturais ${ }^{9}$. Por sua vez, o PCIC destina três capítulos ao desenvolvimento da dimensão cultural, nesta ocasião, com descritores específicos: o capítulo dedicado a referentes culturais, o centrado nos saberes e comportamentos socioculturais e o último, em que aborda as habilidades e atitudes interculturais.

9 Especialmente nos capítulos 2.1. e 5.1. 
O grupo PACTE (Procés d'Adquisició de la Competència Traductora i Evaluació) trabalha num projeto designado "Nivelación de competencias en la adquisición de la competencia traductora (traducción escrita)"10, onde propóe, à semelhança do Quadro europeu comum de referência para as línguas, estabelecer os níveis de competência na adquisição de competências de tradução. Os investigadores sugerem descrever e definir as competências específicas que intervêm na competência tradutora, bem como os resultados de aprendizagem de cada nível. A proposta indica três níveis e cada um deles incluiria a competência linguística, a extralinguística, a instrumental, a estratégica e os conhecimentos de tradução. Tal como acontece com $Q E C R L$, a adoção e aplicação didática de uma descrição deste género proporcionaria um quadro comum com critérios unificados para ser aplicado na formação de tradutores, com orientações curriculares, programas, critérios de avaliação, materiais de ensino, etc.

As investigações sobre a tradução de EC proporcionam um interessante e inexplorado potencial de aplicação na formação de tradutores, porquanto são um elemento de documentação em contexto profissional e de formação. Encontramos vantagens na utilização das pesquisas como apoio documental útil para consulta de estudantes e docentes, já que o recurso a dados e referências concretas permite a tomada de decisóes fundamentadas com base nos estudos, abandonando o lugar de crenças ou intuiçôes individuais. Aliás, as investigações garantem elementos concretos 10 Disponível em: <http://ddd.uab.cat/pub/presentacions/2016/166679/PACTE_ didTRAD2016.pdf>. 
extraídos de corpora e orientam sobre as normas de tradução vigentes numa determinada modalidade de tradução, em contextos culturais e espaçotemporais concretos. Podem operar como bases de dados e deste modo completar a indicação sobre o significado e o valor de um EC obtida através de internet, dicionários, textos paralelos, etc. Além de tudo, fornecem exemplos de casos representativos e significativos sobre técnicas de tradução usadas na resolução de problemáticas semelhantes.

Em contexto de aula, principalmente em níveis superiores, sugerimos a realização de tarefas e projetos em grupos reduzidos de três ou quatro elementos. A dinâmica de trabalho é o método colaborativo, que comporta um alto grau de responsabilidade e autonomia do estudante na sua aprendizagem. $\mathrm{O}$ trabalho se realiza em ambiente de negociação, não prescritivo.

Como exemplo de uma aplicação, descrevemos uma possível tarefa, que consiste em legendar um fragmento de um filme que contenha uma alta densidade de EC. Começamos por distribuir pelos grupos fragmentos de filmes em versão original. O primeiro desafio será identificar os EC, o que implicará que os estudantes tenham consciência da sua presença e os reconheçam. A seguinte tarefa será investigar o significado e o valor dos EC desconhecidos, a fim de poder valorar a funcionalidade no texto. A seguir, cada grupo discutirá as opções de tradução para cada ocorrência, até chegar a soluçôes consensuais. $\mathrm{O}$ momento seguinte será dedicado a apresentar o resultado do trabalho para o resto da turma, que terá trabalhado com fragmentos semelhantes (pertencentes ao mesmo 
realizador e idêntico contexto linguístico e cultural) e poderá intervir na discussão. Seguidamente, os grupos contrastarão as suas propostas com as legendas feitas por profissionais, que serão vistas apenas como um possível texto final e não como um modelo único válido. $\mathrm{Na}$ fase final, o professor extrairá do corpus resultante da investigação as ocorrências que considere oportunas e apresentará dados quantitativos resultantes da pesquisa.

Como indicámos, esta é apenas a proposta de uma unidade didática estruturada em pequenas tarefas conducentes a uma tarefa final.

Para finalizar, queremos insistir na ideia de que há uma perceção de proximidade entre o espanhol e o português maior da que realmente existe, o que potencia o grau de interferência nas traduçóes e alguma intrusão profissional. Para corrigir a tendência, Cintrão sugere "um treinamento contrastivo mais ostensivo nos níveis sintático, discursivo e cultural" (Cintrão 2006, 101), onde se trabalhem habilidades e estratégias cognitivas que contrabalancem a tendência. De facto, na didática de línguas próximas, Calvo (2006) propóe o recurso à tradução como meio de conscientização contrastiva para diminuir as interferências entre as duas línguas.

\section{REFERÊNCIAS BIBLIOGRÁFICAS}

Barambones Zubiria, Josu. La traducción audiovisual en ETB-1: estudio descriptivo de la programación infantil y juvenil. Tese de doutoramento da Euskal Herriko Unibertsitatea: 2009. Disponível em: <https://addi.ehu.es/ bitstream/10810/12182/1/barambones.pdf>. Acesso em 10 jul. 2017.

Calvo Capilla, Carolina; Ridd, Mark. "A tradução como atividade contrastiva e de conscientização na aprendizagem de línguas próximas". In: Horizontes de Lingüistica Aplicada, vol. 8, n. 2, 2006, 150-169. 
Chaume Varela, Frederic; García de Toro, Cristina. Teories actuals de la traductologia. Alzira: Bromera, 2010.

Cerezo Merchán, Beatriz. La didáctica de la traducción audiovisual en España: un estudio de caso empirico-descriptivo. Tese de doutoramento, Universitat Jaume I, Castelló: 2012.Disponível em: <http://www.tesisenred.net/ handle/10803/83363>. Acesso em 10 jul. 2017.

Cifuentes Férez, Paula. "Las diez competencias fundamentales para la empleabilidad según egresados, profesorado y profesionales de la traducción y la interpretación”. In: Quaderns: revista de traducció, 24, 197-216, 2017. Disponível em: <http://www.raco.cat/index.php/QuadernsTraduccio/article/ view/321770>. Acesso em 10 jul. 2017.

Cintrão, Heloísa Pezza. "Competência tradutória, línguas próximas, interferência: efeitos hipnóticos em tradução direta”. In: TradTerm, 12, 2006, 69-104. Disponível em: <http://www.revistas.usp.br/tradterm/article/view/52262>. Acesso em 10 jul. 2017.

Conselho da Europa. Quadro europeu comum de referência para as línguas. Aprendizagem, ensino, avaliação. Porto: Edições Asa, 2001.

Delabastita, Dirk. "Translation and Mass-communication: Film and T.V. Translation as Evidence of Cultural Dynamics”. In: Babel, vol. 35, n. 4, 1989, 193-218.

Díaz-Cintas, Jorge. “Teoría y traducción audiovisual”. In: Zabalbeascoa Terran, Patrick; Santamaría Guinot, Laura; Chaume Varela, Frederic (eds.). La traducción audiovisual. Investigación, enseñanza y profesión. Granada: Comares, 2005, 9-21.

Diaz Fouces, Oscar. "Algumas considerações sobre a combinação linguística português-espanhol". In: Diaz Fouces, Oscar (ed.). Olhares \& Miradas. Reflexiones sobre la traducción portugués-español y su didáctica. Granada: Atrio, 2012, 119-135. 
Gutiérrez Bregón, Silvia. "La competencia intercultural en la profesión del traductor: aproximación desde la formación de traductores y presentación de un estudio de caso". In: Trans, 10, 2016, 57-74.

Kelly, Dorothy. "La competencia traductora: bases para el diseño curricular”. In: Puentes, 1, 2002, 9-20.

PACTE. "Building a Translation Competence Model". In: Alves, Fabio (ed.). Triangulating Translation: perspectives in process oriented research. Amsterdam: John Benjamins, 2003, 43-66.

PACTE. "Establishing competence levels in translation". 2016. Disponível em: $<$ http://ddd.uab.cat/record/166683>. Acesso em 10 jul. 2017.

Poyato Sánchez, Pedro. Guía para ver y analizar. Todo sobre mi madre: Pedro Almodóvar. Valencia: Naullibres, Octaedro, 2007

Skuggevik, Erik. "Teaching Screen Translation: The role of Pragmatics in Subtitling". In: Díaz-Cintas, Jorge; Anderman, Gunilla (eds.). Audiovisual Translation. Language Transfer on Screen. London: Palgrave Macmillan, 2009, 197-213.

Toury, Gideon. Descriptive translation studies and beyond. Amsterdam: John Benjamins, 1995. 